\title{
REVIEW ARTICLE The impact of cannabinoid type 2 receptors (CB2Rs) in neuroprotection against neurological disorders
}

\author{
Qing $\mathrm{Xin}^{1,2}$, Fei $\mathrm{Xu}^{3}$, Devin H. Taylor ${ }^{4}$, Jing-fu Zhao ${ }^{1}$ and Jie $\mathrm{Wu}^{1}$
}

Cannabinoids have long been used for their psychotropic and possible medical properties of symptom relief. In the past few years, a vast literature shows that cannabinoids are neuroprotective under different pathological situations. Most of the effects of cannabinoids are mediated by the well-characterized cannabinoid receptors, the cannabinoid type 1 receptor (CB1R) and cannabinoid type 2 receptor (CB2R). Even though CB1Rs are highly expressed in the central nervous system (CNS), the adverse central side effects and the development of tolerance resulting from CB1R activation may ultimately limit the clinical utility of CB1R agonists. In contrast to the ubiquitous presence of CB1Rs, CB2Rs are less commonly expressed in the healthy CNS but highly upregulated in glial cells under neuropathological conditions. Experimental studies have provided robust evidence that CB2Rs seem to be involved in the modulation of different neurological disorders. In this paper, we summarize the current knowledge regarding the protective effects of CB2R activation against the development of neurological diseases and provide a perspective on the future of this field. A better understanding of the fundamental pharmacology of CB2R activation is essential for the development of clinical applications and the design of novel therapeutic strategies.

Keywords: cannabinoid; cannabinoid type 2 receptor; neuroprotection; ischemic stroke; Alzheimer's disease; Parkinson disease Acta Pharmacologica Sinica (2020) 41:1507-1518; https://doi.org/10.1038/s41401-020-00530-2

\section{INTRODUCTION}

The endocannabinoid (eCB) system is defined as the ensemble of the two 7-transmembrane-domain G-protein-coupled receptors (CB1R and CB2R) for $\Delta(9)$-tetrahydrocannabinol; their two most studied endogenous ligands, namely, the "endocannabinoids" $\mathrm{N}$-arachidonoylethanolamine (anandamide) and 2-arachidonoylglycerol (2-AG); and the enzymes responsible for endocannabinoid metabolism [1]. The eCB system has recently attracted attention for its roles in various behavioral and brain functions and as a therapeutic target for neuropsychiatric, neurodegenerative, and neurological diseases [2-4]. However, these therapeutic efforts have been marked by disappointment, especially in relation to the serious psychiatric side effects, including anxiety, depression and even suicidal ideation from activation of CB1Rs $[5,6]$, which have limited the therapeutic use of drugs that activate or inactivate this receptor. Accumulating lines of evidence have shown the therapeutic potential of CB2R ligands and indicated new possibilities for safe targeting of this endocannabinoid system. CB2R is a G-protein-coupled receptor that was cloned in 1993 [7]. Since then, the expression and function of CB2Rs in the brain have been debated. Early studies suggested that CB2R was absent in the brain because mRNA transcripts of CB2Rs were not detected in brain tissues with various methods [811]. Based on these findings, $C B 2 R$ has been considered a "peripheral" cannabinoid receptor. Recently, this concept was challenged by the identification of CB2Rs throughout the central nervous system (CNS). Interested readers are referred to the excellent reviews written by Atwood et al. [12], Jordan et al. [13], Cristino et al. [4], and Reddy et al. [14] for comprehensive overviews regarding the progress of research on the cannabinoid system, especially CB2Rs, in the CNS. Compared with CB1Rs, brain CB2Rs exhibit several unique features. (1) CB2R has lower expression levels than CB1R in the brain, suggesting that CB2Rs may not mediate the effect of cannabis under normal physiological conditions. (2) CB2R is highly inducible; thus, under some pathological conditions (e.g., addiction, inflammation, anxiety, etc.), CB2R expression is enhanced in the brain [15]. This suggests a close relationship between the alteration of CB2R expression/ function and various psychiatric and neurological diseases. (3) CB2Rs have a unique distribution. Given that they are chiefly expressed in neuronal somatodendritic areas (postsynaptic) [16], the activation of CB2Rs may lead to opposing effects from those of CB1Rs, as CB1Rs are predominantly expressed on neuronal terminals, especially on GABAergic terminals (presynaptic) [17]. Considering these characteristics, CB2Rs appear to be an important substrate for neuroprotection [18], and targeting CB2Rs will likely offer a novel therapeutic strategy for treating neuropsychiatric and neurological diseases without typical CB1Rmediated side effects (including depression, anxiety, and suicidal thoughts) $[19,20]$. Thus, an urgent need to understand the functional effects of CB2Rs in the brain has emerged. Extensive evidence supports the implication of the mesocorticolimbic

\footnotetext{
'Institute of Brain Science and Diseases, and Department of Physiology, School of Basic Medicine, Qingdao University, Qingdao 266071, China; ${ }^{2}$ Institute of Neurobiology, Jining Medical University, Jining 272000, China; ${ }^{3}$ Department of Vascular Surgery, Jining No.1 People's Hospital, Jining 272000, China and ${ }^{4}$ Department of Biology, Utah Valley University, Orem, UT, USA

Correspondence: Jie Wu (jiewu2@qdu.edu.cn)

These authors contributed equally: Qing Xin, Fei Xu
}

Received: 14 May 2020 Accepted: 6 September 2020

Published online: 6 October 2020 
dopamine (DA) system as a key brain circuit involved in a number of drug addictions. Alteration of the mesocorticolimbic DA circuit is the major cellular mechanism involved in promoting or preventing drug reward, dependence, and addiction. Emerging evidence demonstrates that CB2Rs mediate important modulations in drug-seeking behaviors in animals, including behaviors associated with cocaine, alcohol, and nicotine [21-23]. This suggests a significant impact of brain CB2Rs on animal drug reward, dependence, and addiction. Given the lack of psychoactivity demonstrated by selective CB2R agonists, CB2R ligands have been developed as new candidates for treating a variety of neurological and psychiatric disorders, including pain, neuroinflammation, stroke, Alzheimer's disease (AD), Parkinson's disease (PD), and Huntington's disease (HD). At the practical level, three medicines that activate the cannabinoid receptors CB1R/CB2R are now used in clinics: Cesamet (nabilone), Marinol (dronabinol; $\Delta^{9}$ tetrahydrocannabinol $\left[\Delta^{9}\right.$-THC]), and Sativex ( $\Delta^{9}$-THC with cannabidiol). To date, there is no highly selective CB2R agonist available in clinical medicine. However, significant attention is currently being paid to the possibility of developing medicines from compounds that can activate CB2Rs at doses that induce little or no CB1R activation. This research was triggered by the evidence that many of the adverse effects induced by mixed CB1R/CB2R agonists result from $C B 1 R$ activation, rather than from $C B 2 R$ activation, and that CB2R-selective agonists have a number of important potential therapeutic applications [24]. Many highly selective compounds of various chemotypes have been identified, and several companies have initiated clinical trials. Therefore, we anticipate the emergence of new drugs from CB2R modulations once a better understanding of the cannabinoid receptors is gained. In this paper, we first provide a broad overview of CB2R expression and function in the brain, then discuss preclinical and clinical studies of CB2R-based drugs as potential therapeutic agents for a variety of neurological disorders in detail.

\section{EXPRESSION OF CB2RS IN THE CENTRAL NERVOUS SYSTEM}

CB2Rs were formerly considered to be exclusively peripheral cannabinoid receptors, restricted mainly to peripheral tissues and particularly immune cells, regulating immune responses and inflammation [8,9]. Although initial studies were not able to detect the expression of CB2Rs in the brain, compelling evidence has demonstrated decentralized expression of CB2Rs, with their presence detected on neuronal, glial, and endothelial cells in various brain regions, including the cerebral cortex, hippocampus, thalamus, midbrain, pons, medulla, brain stem and cerebellum [25-31]. In neurons, CB2R's immunoreactivity was observed in somata, as well as large and medium-sized dendrites [32, 33]. Labeling of CB2Rs was also found to be associated with the plasma membrane in immunoreactive glial and endothelial cells $[25,26,29]$.

Moreover, there are clear species-based differences in CB2Rs among humans, mice, and rats in terms of mRNA size in tissues and cell lines. Human CB2R (hCB2R) and mouse CB2R (mCB2R) genes are transcribed to yield two isoforms each, that is, hCB2A and $h C B 2 B$ and $m C B 2 A$ and $m C B 2 B$, respectively, while the rat $C B 2 R$ (rCB2R) gene is transcribed to yield at least four isoforms, namely, rCB2A, rCB2B, rCB2C, and rCB2D [34]. The species-based differences in $C B 2 R$ gene and receptor expression in the brain may partly explain why initial studies were not able to detect CB2R expression in both human and rodent brains. Human CB2A mRNA expression was observed predominantly in the testis, where the expression level was more than 100-fold lower that in the spleen and leukocytes. Human CB2A expression was also observed in the human caudate nucleus, amygdala, hippocampus, cerebellum, nucleus accumbens, putamen, and cortex of the brain, with similar levels of expression in peripheral tissues, such as muscle and spleen. In contrast, CB2B mRNA could not be detected in brain regions at a significant level and is predominantly expressed in spleen and leukocytes [35]. In mice, both mCB2A and mCB2B isoform transcripts were detected in brain regions such as the frontal cortex, striatum, and brain stem at $\sim 1 \%$ of the spleen expression level $[34,35]$. rCB2R mRNA was also present in some brain areas (retina, cerebellum, cortex, and brainstem) of rats $[30,36]$. In situ hybridization RNAscope assays found higher levels of CB2R mRNA in different brain regions and cell types in mice than in rats. CB2R mRNA levels in tyrosine hydroxylase (TH)positive dopamine (DA) neurons and TH-negative cells were very similar in mouse ventral tegmental areas (VTAs) but were significantly lower in dopamine transporter (DAT)-positive DA neurons than DAT-negative neurons in rat VTAs, suggesting species-based differences in CB2R mRNA expression in VTA DA neurons [37].

Generally, the expression of CB2Rs in the CNS has been found in many different types of cells, e.g., neurons [38], glial cells [39, 40], endothelial cells [26], retinal ganglion cells [36, 41] and neural progenitor cells [42]. The expression data of CB2R mRNA and protein in the CNS have been compiled in both Tables 1 and 2, from general distribution to cellular and subcellular localization.

\section{NEUROPROTECTIVE ROLE OF CB2RS IN ISCHEMIC STROKE}

Stroke is the second most common cause of death and the third leading cause of disability worldwide (see Tables 3 and 4), and ischemic stroke accounts for $\sim 87 \%$ of all strokes [43]. The final consequence of stroke is patient death or disability characterized by multiple cognitive, motor and psychiatric problems associated with a major sanitary and socioeconomic burden. Despite significant advances in the development of neuroprotective compounds for ischemic stroke, recombinant tissue plasminogen activator (rt-PA) and endovascular thrombectomy are currently available to only a small subpopulation of stroke victims [44].

Considering the critical role of inflammation in the pathogenic progression of postischemic neuronal damage and the antiinflammatory therapeutic potential of CB2Rs observed in several peripheral organs and CNS diseases, CB2R has drawn great attention as a potential therapeutic target for the treatment of ischemic stroke. Early activation of CB2Rs has been observed in animal models of stroke, and the binding levels of the CB2R tracer $\left[{ }^{11} \mathrm{C}\right]$ NE40 were significantly higher in the cerebral cortical region on the lesion side than on the non-lesioned side in a photothrombotic stroke model [45]. Moreover, the selective CB2R agonists (O-3853, O-1966) caused a reduction in white blood cell rolling and adhesion along cerebral vascular endothelial cells, reduced infarct volumes and improved motor function in a mouse focal ischemia/reperfusion model [46]. Treatment with O1966 contributed to protecting the brain through the attenuation of cerebral microcirculatory dysfunction, such as increased leukocyte/endothelial interactions, upregulation of adhesion molecule expression and disruption of the blood-brain barrier (BBB) [47]. In addition, it has been shown that the CB2R agonist JWH-133 protects against cerebral ischemia by inhibiting the recruitment of neutrophils to brain endothelial cells and the chemotaxis of neutrophils [48], ameliorating mitochondrial depolarization through modulation of AMPK/CREB signaling [49] and suppressing hypoxia-induced activation of the NF-KBdependent neuroinflammatory pathway in microglial cells [50]. Recent research demonstrated, in a gerbil model of transient cerebral ischemia, that $\mathrm{N}$-linoleyltyrosine, as an anandamide analog, could improve motor coordination, alleviate learning and memory impairments, attenuate ischemia-induced neural loss in the hippocampus and decrease inflammation in mice via the PI3K/Akt signaling pathway by activating CB2R [51].

Some studies have suggested that the effectiveness of CB2R agonists in animal models of stroke is affected by treatments. Delayed treatment with a CB2R agonist, AM1241, failed to 
Table 1. Protein expression of CB2Rs in the CNS.

\begin{tabular}{|c|c|c|c|c|}
\hline Brain region & Cell types & Subcellular localization & Species & Ref \\
\hline Olfactory tubercle & Neurons & & Healthy SD rats & {$[25]$} \\
\hline Cerebral cortex: (layers III and v) & Pyramidal neurons & Cell body and apical dendrite & Healthy SD rats & {$[25]$} \\
\hline $\begin{array}{l}\text { Hippocampus: CA1 } \\
\text { CA2, CA3 and subiculum }\end{array}$ & $\begin{array}{l}\text { Neurons } \\
\text { Gila cells } \\
\text { Endothelial cells } \\
\text { Pyramidal neurons }\end{array}$ & $\begin{array}{l}\text { Cell body and dendrite } \\
\text { Plasma membrane } \\
\text { Plasma membrane }\end{array}$ & $\begin{array}{l}\text { Healthy SD rats } \\
\text { Healthy SD rats } \\
\text { Healthy SD rats } \\
\text { Healthy SD rats }\end{array}$ & $\begin{array}{l}{[26,29]} \\
{[26,29]} \\
{[26,29]} \\
{[25]}\end{array}$ \\
\hline Thalamus & & Cell body & Healthy SD rats & [25] \\
\hline Hypothalamus & & Cell body & Healthy SD rats & [25] \\
\hline $\begin{array}{l}\text { Midbrain: (periaqueductal gray, paratrochlear } \\
\text { nucleus, paralemniscal nucleus, red nucleus, } \\
\text { amygdala, geniculate nucleus and } \\
\text { interpeduncular nucleus, inferior colliculus, } \\
\text { substantia nigra) }\end{array}$ & $\begin{array}{l}\text { Neurons } \\
\text { Glial and endothelial cells }\end{array}$ & $\begin{array}{l}\text { Cell body and dendrite } \\
\text { Plasma membrane and some } \\
\text { unmyelinated axons }\end{array}$ & $\begin{array}{l}\text { Healthy SD rats } \\
\text { Healthy SD rats }\end{array}$ & $\begin{array}{l}{[25,26]} \\
{[26]}\end{array}$ \\
\hline Pons: (pontine nucleus) & Astrocytes or microglial cells & Cell processes & Healthy SD rats & {$[25]$} \\
\hline Medulla: & Neurons & Cell body & Healthy SD rats & {$[25]$} \\
\hline Brain stem: & Neurons & & Healthy wistar rats, ferret & {$[28,30]$} \\
\hline $\begin{array}{l}\text { Cerebellum: (molecular layers. Purkinje cell } \\
\text { layers, the granule layers) }\end{array}$ & $\begin{array}{l}\text { Neurons } \\
\text { Endothelial cells } \\
\text { Perivascular microglial cells }\end{array}$ & Cell body and dendrite & $\begin{array}{l}\text { Healthy rats, ferret } \\
\text { Healthy rats } \\
\text { Post-mortem brain }\end{array}$ & $\begin{array}{l}{[25,30]} \\
{[27]} \\
{[31]}\end{array}$ \\
\hline $\begin{array}{l}\text { Retina: (segment of photoreceptor Layer, Outer } \\
\text { nuclear layer, Henle fiber layer, outer plexiform } \\
\text { layer, inner nuclear layer, inner plexiform layer, } \\
\text { ganglion cell layer) }\end{array}$ & $\begin{array}{l}\text { Cones } \\
\text { Rods } \\
\text { Müller cells } \\
\text { Horizontal cells } \\
\text { Rod bipolar cells } \\
\text { Cone bipolar cells } \\
\text { Amacrine cells } \\
\text { Ganglion cells }\end{array}$ & $\begin{array}{l}\text { Cell body } \\
\text { Cell body } \\
\text { Cell fiber } \\
\text { Soma and dendrite } \\
\text { Soma and dendrite } \\
\text { Soma } \\
\text { Soma } \\
\text { Soma and nuclei }\end{array}$ & $\begin{array}{l}\text { Healthy mice } \\
\text { Healthy mice } \\
\text { Healthy SD rats and monkeys } \\
\text { Healthy mice } \\
\text { Healthy mice } \\
\text { Healthy mice } \\
\text { Healthy mice } \\
\text { Healthy mice and monkey }\end{array}$ & $\begin{array}{l}{[150]} \\
{[150]} \\
{[151,152]} \\
{[150]} \\
{[150]} \\
{[150]} \\
{[150]} \\
{[150,152]}\end{array}$ \\
\hline
\end{tabular}

suppress brain damage after stroke. In contrast, pretreatment with AM1241 significantly reduced the area of infarction and neurological deficits [52]. Similar reports have also indicated that pretreatment with 0-1966 was protective against cognitive impairments and neuronal tissue damage after permanent cerebral ischemia but may also influence the neuronal or glial function of learning and memory circuits in the uninjured brain [53]. CB2Rs in microglial cells following hypoxia-ischemia $(\mathrm{HI})$ insult act as a neuroprotective mechanism to prevent inflammation mediated through modulation of the inflammation-related HIF-1a/TIM-3 signaling pathway [54]. Furthermore, CB2Rs were also found to be fundamental for driving neurogenesis by promoting neuroblast migration toward the boundary of the infarct area, increasing the number of new cortical neurons and improving functional outcome after stroke [55]. Regarding the underlying molecular mechanisms, CB2R activation has been shown to inhibit neuroinflammation, attenuate neuronal tissue damage, drive neurogenesis and improve motor function and memory impairment. Overall, the neuroprotective effects of CB2Rs in ischemic stroke pathogenesis present a novel promising therapeutic strategy that might overcome the limitations of current stroke treatment.

NEUROPROTECTIVE ROLE OF CB2RS IN ALZHEIMER'S DISEASE Alzheimer's disease (AD) is the most common progressive neurodegenerative disease in the aged population and is characterized by abnormal accumulation of $\beta$-amyloid $(A \beta)$ in senile plaques in the brain. The excessive deposition of $A \beta$ triggers neurodegeneration, synaptic dysfunction, inflammation, and microvascular alterations, which can eventually lead to cognitive impairment, memory loss, and behavioral changes [56].

Emerging evidence indicates the involvement of CB2Rs in the pathological progression of $A D$. There is a great deal of experimental evidence demonstrating that CB2R is expressed at very low turnover rates in the healthy CNS, but the expression of CB2Rs is highly induced in plaque-associated microglial cells and astrocytes in brain tissues from AD patients and in genetic mouse models expressing pathogenic variants of amyloid precursor protein (APP) [57-60]. Interestingly, it seems that CB2R correlates with two relevant $A D$ molecular markers, namely, $A \beta_{42}$ levels and senile plaque score, even though cognitive status shows no correlation [61]. Moreover, CB2Rs might be a suitable target for the development of PET radiotracers that could serve as a biomarker for neuroinflammation in the early preclinical stages of $A D$, when no significant neuronal loss has yet developed [62].

Previously, it was observed that a lack of CB2Rs enhanced the level of Iba1 staining and exacerbated soluble $A \beta_{42}$ and plaque deposition, which might confirm the constitutive role of CB2Rs in reducing amyloid plaque pathology in $A D$ [63]. Pharmacological activation of CB2Rs with JWH-015 was also able to induce the removal of $A \beta$ plaques from human $A D$ tissue sections by human THP-1-derived macrophages via inhibition of the secretion of IL-1 $\beta$ and TNF-a [64]. The specific CB2R agonist JWH-133 could improve cognitive impairment, inhibit neuroinflammation and oxidative stress responses, and lower tau hyperphosphorylation in the vicinity of $A \beta$ plaques when administered presymptomatically [65]. Moreover, JWH-133 could also improve the endothelialdependent relaxations impaired by $A \beta$ and exert vasodilatory effects that were maintained in Tg APP mice, thus being beneficial in the treatment of $A D$ [66]. Similarly, pharmacological studies in rodents have also identified a crucial role of CB2Rs in $A D$ associated inflammatory processes, demonstrating that treatment with 1-((3-benzyl-3-methyl-2,3-dihydro-1-benzofuran-6-yl) carbonyl) piperidine (MDA7), a novel selective CB2R agonist, suppressed the activation of microglial cells and astrocytes, decreased the upsurge of $C B 2 R$, and promoted the clearance of $A \beta$, which eventually promoted recovery of neuronal synaptic plasticity and improved cognition and memory in $A D$ models $[67,68]$. In addition, both selective (JWH-133) and nonselective (WIN55212-2) CB2R agonists, but not a CB1R-selective agonist (ACEA), stimulated glucose uptake in the mouse brain, increasing the therapeutic interest in CB2R agonists as nootropic agents [69]. Furthermore, a recent study reported that $\mathrm{CB} 2 \mathrm{R}$ activation by $\mathrm{JWH}-015$ played a beneficial role in novel object recognition ability concomitant with region-specific regulation in microglia-mediated 
neuroinflammation and dendritic complexity in $A D$ model mice [70]. These results may constitute the basis of CB2R-based therapies or diagnostic approaches for AD.

Although CB2R has been thought to play an important role in neuroinflammatory responses and has been proposed as a therapeutic target for $A D$, the exact mechanism of $C B 2 R$ signaling in $A D$ remains elusive. Moreover, conflicting results have also been reported wherein $C B 2 R$ is not required for ameliorating neuropathy or preventing cognitive decline by inhibiting 2arachidonoylglycerol (2-AG, a full agonist of CB1R and CB2R) metabolism in AD model animals [71]. Similarly, the antiinflammatory and neuroprotective effects of pharmacological and genetic inhibition of 2-AG metabolism were not mediated by CB1Rs or CB2Rs [72]. In another study, researchers suggested that $C B 2 R$ s participated in $A \beta$ processing in a mouse model of $A D$ and played a minor role in the therapeutic properties of a cannabisbased medicine, as CB2R deficiency did not affect the viability of $A \beta P P / P S 1$ transgenic mice, did not accelerate memory impairment, did not modify tau hyperphosphorylation in dystrophic neurites associated with $A \beta$ plaques, and did not attenuate the positive cognitive effect induced by cannabis-based medicine in these animals [73]. Interestingly, Schmöle et al. [74] found that microglial cells harvested from $\left.\mathrm{CB} 2 \mathrm{R}^{-} /^{-}\right)$mice were less responsive to proinflammatory stimuli than $\mathrm{CB} 2 \mathrm{R}\left({ }^{+} /{ }^{+}\right)$microglial cells harvested from wild-type mice. Transgenic APP/PS1 mice lacking CB2Rs showed reduced percentages of microglial cells and infiltrating macrophages, lower expression levels of proinflammatory chemokines and cytokines in the brain, and diminished concentrations of soluble $A \beta_{40 / 42}$. Recently, the authors further reported that the genetic deletion of $C B 2$ Rs improved cognitive and learning deficits in $\mathrm{APP} / \mathrm{PS} 1{ }^{*} \mathrm{CB} 2 \mathrm{R}^{-} /^{-}$mice, which was accompanied by reduced neuronal loss and decreased plaque levels, which coincided with increased expression of $A \beta$-degrading enzymes. In addition, plaque-associated microglial cells in APP/ $\mathrm{PS} 1{ }^{*} \mathrm{CB} 2 \mathrm{R}^{-} /^{-}$mice showed a less activated morphology, while the plaques were smaller and more condensed than those in APP/PS1 mice [58]. These divergent results from previous studies reflected the complex roles of CB2Rs in the neuropathology and pathogenesis of AD. Nevertheless, CB2R might serve as a new potential therapeutic target for preventing, alleviating and treating $A D$ through several mechanisms. CB2Rs appear to be part of a protective system that might be detrimental when engaged continuously. Further research is needed to elucidate the potential molecular mechanisms.

NEUROPROTECTIVE ROLE OF CB2RS IN PARKINSON'S DISEASE Parkinson's disease (PD) is the second most common neurodegenerative disease and the most common motor disorder affecting millions of people worldwide [75]. Loss of the neurotransmitter dopamine has been regarded as the major pathological characteristic of PD, leading to motor dysfunction and cognitive impairment. However, until now, there has been no fully effective therapy developed to treat the clinical syndromes of $P D$, as current pharmacotherapies could only temporarily relieve PD symptoms but not prevent or slow down disease progression. There are several reports that describe the potential roles of CB2Rs as a viable target for anti-inflammatory therapy for PD. CB2R levels were significantly elevated in animal models of PD, and this increase correlated significantly with an increase in microglial activation [76]. Moreover, postmortem studies of human patients with PD have revealed that the expression of CB2R is elevated in microglial cells recruited and activated at lesioned sites in the substantia nigra of PD patients [39]. In short, the expression of CB2Rs in glial cells is upregulated in PD, but this receptor may also be located in certain neuronal subpopulations and serve as a marker of neuronal loss. For instance, García et al. observed that CB2R was located in TH-containing neurons in the substantia nigra 
at levels significantly lower in PD patients than in controls [77]. Similarly, mice with 1-methyl-4-phenyl-1,2,3,6-tetrahydropyridine (MPTP)-induced parkinsonian syndrome also showed a downregulation of the $C B 2 R$ protein in the substantia nigra and hippocampus three weeks after MPTP injection [78]. Additionally, CB2R-deficient mice displayed intense activation of microglial cells and much more intense deterioration of TH-containing nigral neurons in the case of the substantia nigra in models of PD, which supported the potential neuroprotective role of this receptor [39]. One in vivo study has also shown that pharmacological activation of $\mathrm{CB} 2 \mathrm{Rs}$ with the nonselective cannabinoid receptor agonist WIN55,212-2 or the CB2R agonist JWH-015 protected against MPTP-induced nigrostriatal degeneration by inhibiting microglial activation/infiltration [79]. In addition, the selective CB2R agonist AM1241 has been shown to have a significant therapeutic effect on PD and regenerate DA neurons after the neurotoxic effect of MPTP treatment. The possible mechanisms underlying the neurogenic effect of AM1241 might be the induction of CB2R expression and an increase in phosphorylation of the PI3K/AKT signaling pathway [78]. Similar findings were observed in an LPSinduced animal model of PD after administration of $\Delta 9$ tetrahydrocannabivarin (THCV), which has antioxidant properties and the ability to activate CB2Rs and block CB1Rs. In another animal model of PD induced by rotenone (ROT), the authors reported that treatment with $\beta$-caryophyllene $(B C P)$, a natural CB2R agonist, attenuated oxidative/nitrosative stress and neuroinflammation, inhibited gliosis and proinflammatory cytokine release, and decreased nigrostriatal degeneration [80]. Furthermore, it has been shown recently that the use of BCP offers significant protection against 1-methyl-4-phenylpyridinium (MPP)induced neurotoxicity by activating a cellular redox enzyme system [81, 82]. In summary, agonists of CB2Rs that exert antioxidant and anti-inflammatory activities might have promising pharmacological profiles for ameliorating parkinsonian symptoms and delaying disease progression in PD.

\section{NEUROPROTECTIVE ROLE OF CB2RS IN HUNTINGTON'S DISEASE}

Huntington's disease (HD) is a genetic neurodegenerative disease caused by the expansion of a CAG triplet repeat in the gene encoding the protein huntingtin, which results in neuron degeneration mainly in the striatum. This leads to abnormal motor movements (chorea) and cognitive decline [83]. Currently, no successful treatment is known to prevent or slow the progression of HD. However, it is worth noting that CB2R is emerging as a new therapeutic target for the treatment and early diagnosis of different neurodegenerative disorders, including HD [84]. In the transgenic R6/2 Huntington chorea mouse model, the expression of CB2Rs was increased in the hippocampus, cortex, striatum and cerebellum, as shown by real-time polymerase chain reaction [85]. The upregulation of CB2Rs was also observed in striatal microglial cells of HD transgenic mouse models and in the caudate nucleus/putamen from HD patients. Notably, genetic ablation of CB2Rs in R6/2 mice enhanced microglial activation, aggravated disease symptomatology and reduced mouse lifespans. Likewise, microglial CB2Rs exerted neuroprotective effects against $\mathrm{HD}$ excitotoxicity by reducing neuroinflammation, brain edema, striatal neuronal loss and motor symptoms [86]. In line with these findings, a Sativex-like phytocannabinoid combination was capable of delaying signs of disease progression in a proinflammatory model of HD generated by intrastriatal injection of malonate in a CB1R- and CB2R-dependent manner. The role of CB2Rs was further confirmed by two observations: CB2R-deficient mice were more sensitive to malonate than wild-type animals [87], and genetic deletion of CB2Rs both accelerated the onset of motor deficits and increased their severity [88]. However, the authors found that treatment with GW405833, a high-affinity and 
Table 4. Neuroprotective effects of selective CB2R ligands.

\begin{tabular}{|c|c|c|c|}
\hline Agonists & $\mathrm{Ki}(\mathrm{nM}) / \mathrm{CBR}$ & Neuroprotective effects & Ref \\
\hline AM1241 & $\begin{array}{l}280 / C B 1 R \\
3.4 / C B 2 R\end{array}$ & $\begin{array}{l}\text { Reducing cerebral infarction and neurological deficits; regenerating DA neurons } \\
\text { after MPTP treatment; slowing motor neuron degeneration and preserving motor } \\
\text { function and increasing survival interval in ALS model; attenuating mechanical } \\
\text { allodynia. }\end{array}$ & {$[52,104,78,105,139]$} \\
\hline MDA7 & $\begin{array}{l}2565 \pm 695 / C B 1 R \\
238 \pm 143 / C B 2 R\end{array}$ & $\begin{array}{l}\text { Suppressing activation of microglial cells and astrocytes, promoting } A \beta \text { clearance, } \\
\text { promoting neuronal recovery, synaptic plasticity and improving cognition and } \\
\text { memory in } A D \text { models, attenuating mechanical allodynia. }\end{array}$ & {$[67,68,139]$} \\
\hline $\mathrm{BCP}$ & $155 \pm 4 / C B 2 R$ & $\begin{array}{l}\text { Attenuating oxidative/nitrosative stress, neuroinflammation, gliosis and nigrostriatal } \\
\text { degeneration; diminishing axonal demyelination. and modulating Th1/Treg } \\
\text { immune balance; attenuating mechanical allodynia }\end{array}$ & {$[80,101,139]$} \\
\hline GW405833 & $\begin{array}{l}\text { 4772/CB1R 3.92/ } \\
\text { CB2 R }\end{array}$ & $\begin{array}{l}\text { Extending life spans and suppressing neurodegeneration, synapse loss and motor } \\
\text { deficits; attenuating mechanical allodynia }\end{array}$ & {$[88,139]$} \\
\hline HU308 & $\begin{array}{l}>10,000 / \mathrm{CB} 1 \mathrm{R} \\
22.7 / \mathrm{CB} 2\end{array}$ & $\begin{array}{l}\text { Ameliorating EAE symptoms, reducing axonal loss, and inhibiting microglial } \\
\text { activation and reactive astrogliosis }\end{array}$ & {$[96,106]$} \\
\hline
\end{tabular}

highly selective partial CB2R agonist, extended life spans and suppressed neurodegeneration, synapse loss and motor deficits by CB2R signaling not in parenchymal microglial cells but rather in peripheral immune cells [88]. Moreover, Dowie et al. [89] demonstrated that CB2Rs were localized on the CD31-positive blood vessel endothelium and vascular smooth muscle but not expressed on microglial cells or astrocytes in the postmortem brains from HD patients. Although there is ambiguity about the cellular localization of CB2Rs, it could be speculated that selective CB2R agonists might have potential therapeutic value in the treatment of HD. Further mechanistic studies are still warranted to investigate the function of central CB2Rs in HD.

\section{NEUROPROTECTIVE ROLE OF CB2RS IN MULTIPLE SCLEROSIS}

Multiple sclerosis (MS) is an autoimmune disorder of the nervous system characterized by inflammation, neurodegeneration, and demyelination of neurons, which are associated with symptoms such as sensory and motor impairment, ataxia and spasticity. Despite ongoing progress in the understanding of the pathogenesis of MS, new therapeutic approaches are still needed to overcome the lack of effective treatments for this disease, as there is no cure [90]. Among the new therapeutic strategies for the treatment of MS, the modulation of CB2Rs has recently emerged as a promising target for therapeutic intervention [84, 91]. Recently, a significant genetic association was observed between the CB2R rs35761398 (Q63R) polymorphism and MS, which implied the involvement of the CB2R gene in susceptibility to MS [92]. Moreover, several studies confirmed that CB2R expression was upregulated in brain tissues from patients or animal models of MS. Microglial activation was accompanied by the upregulation of CB2Rs at both the mRNA (100-fold) and protein (10-fold) levels compared to microglial cells in the resting state in an experimental autoimmune encephalomyelitis (EAE) mouse model of MS, suggesting that CB2Rs play an important role in the function of microglial cells in the CNS during autoimmune-induced inflammation [93]. Studies performed by Yiangou et al. indicated that human postmortem spinal cord specimens had a significantly greater density of CB2R-immunoreactive microglial cells/macrophages in the white matter in MS sections with lesions, appearing in clusters, usually within the edges of plaque-containing areas [94]. Furthermore, the expression of CB2Rs was found in T lymphocytes, astrocytes, and both perivascular and reactive microglial cells in postmortem brain tissues from donors with MS. Specifically, CB2R-positive microglial cells were evenly distributed within active plaques but were located in the periphery of chronically active plaques [95].

Experimental work has provided robust evidence of the immunomodulatory and neuroprotective properties by activation of CB2R in EAE animal models. CB2R knockout mice showed an exacerbated clinical score of the disease, which occurred in concert with extended axonal loss and microglial activation. In contrast, administration of the CB2R-selective agonist HU-308 markedly ameliorated EAE symptoms, reduced axonal loss, and inhibited microglial activation [96]. Investigations of the effects of O-1966 (a full CB2R agonist) on EAE progression demonstrated that administration of O-1966 resulted in reduced white cell rolling and adhesion to cerebral microvessels, inhibited the invasion of immune cells and improved neurologic function 
after insult [97]. Exogenous administration of the endocannabinoid 2-AG significantly ameliorated the demyelinating and neurodegenerative processes partially through CB2Rs since it delayed disease onset, reduced relapse severity and chronic disability, and eliminated mortality in severe chronic EAE [98]. IL12 and IL-23 are functionally related heterodimeric cytokines that play essential roles in the pathogenesis of MS, and the endocannabinoid anandamide inhibited the IL-12/IL-23 axis through the $\mathrm{ERK}_{1 / 2}$ and JNK pathways in human and murine microglial cells, partially mediated by CB2R activation [99]. In addition, activation of CB2Rs with a CB2R-specific agonist (JWH133) suppressed both mechanical and cold hypersensitivity without producing signs of sedation or ataxia in an EAE mouse model [100]. This was the first preclinical study to directly promote $\mathrm{CB} 2 \mathrm{Rs}$ as a promising target for the treatment of central pain in an animal model of MS. Alberti et al. demonstrated that BCP significantly ameliorated both the clinical and pathological parameters of $E A E$, which seemed to be linked to the ability of BCP to inhibit microglial cells, $\mathrm{CD} 4^{+}$and $\mathrm{CD}^{+} \mathrm{T}$ lymphocytes, as well as the protein expression of proinflammatory cytokines. Furthermore, BCP diminished axonal demyelination and modulated Th1/Treg immune balance through the activation of CB2Rs [101].

Taken together, these observations indicate a neuroprotective role of CB2Rs in EAE pathology. We conclude that nonpsychoactive and selective CB2R agonists possess strong therapeutic potential for the treatment of both neurologic dysfunction and central pain in MS patients.

\section{NEUROPROTECTIVE ROLE OF CB2RS IN AMYOTROPHIC LATERAL SCLEROSIS}

Amyotrophic lateral sclerosis (ALS) is a neurodegenerative disease of unknown etiology characterized by progressive deterioration of both upper and lower motor neurons. Approximately $90 \%$ of ALS cases are sporadic, and $10 \%$ are familial, due to genetic mutations [102]. Currently, there is no effective cure for this illness, with some evidence supporting an improvement in median survival by two to three months with the anti-excitotoxic agent riluzole, which remains the sole treatment option for ALS patients in the US and Europe. This drug has offered modest survival benefits since its approval in the 1990s [103]. Despite significant research efforts, an overwhelming majority of human clinical trials have failed to demonstrate clinical efficacy in the treatment of ALS. More effective drug therapies targeting disease progression are sorely needed.

As shown by several studies [104-106], cannabinoid CB2Rselective compounds may slow motor neuron degeneration, preserve motor function and represent a novel therapeutic modality for the treatment of ALS. Several observations have suggested that CB2Rs were markedly upregulated in activated microglial cells and astrocytes in both patients with ALS and experimental transgenic mouse models of ALS. The upregulation of CB2Rs appeared to occur in activated microglial cells in postmortem human spinal cord specimens from patients with ALS [94] and in spinal gray and white matter areas in TDP-43 transgenic mice at the postsymptomatic stage [107]. Additionally, the mRNA, receptor binding and function of CB2Rs were found to be dramatically and selectively upregulated in the spinal cords of G93A-SOD1 mice in a temporal pattern paralleling disease progression. More importantly, daily injections of the selective CB2R agonist AM1241 initiated at symptom onset increased the survival interval after disease onset by $56 \%$ [104]. CB2R expression was also found to be upregulated predominantly in reactive astrocytes in canine degenerative myelopathy [108] and the postmortem motor cortex of ALS patients [109]. Treatment with AM1241 was effective at slowing signs of disease progression when administered after the onset of these signs in G93A-SOD1 mutant mice [105]. Targeting glial cannabinoid CB2Rs delayed the progression of the pathological phenotype in TDP-43 transgenic mice by improving motor behavior, completely preserving motor neurons in the ventral horn, and attenuating reactive astrogliosis [106]. The CB2R is, therefore, considered a very promising target for therapeutic approaches as well as an imaging tool. To date, by applying in vitro autoradiography, the translational relevance of CB2R imaging was demonstrated with specific binding of $\left[{ }^{11} \mathrm{C}\right] \mathrm{KD} 2$ [110] and $\left[{ }^{11} \mathrm{C}\right] \mathrm{RS}-028[85]$ to postmortem human ALS spinal cord tissues.

\section{MODULATION OF CB2RS IN THE TREATMENT OF EPILEPSY}

Epilepsy is a common chronic neurologic disorder that is characterized by recurrent spontaneous seizures that are associated with an imbalance between excitatory and inhibitory systems in various regions of the brain [111]. Treatment-resistant epilepsy affects $30 \%$ of epileptic patients and is associated with severe morbidity and increased mortality [112]. Accumulating data have demonstrated that cannabinoid systems, including endocannabinoids, anandamide, and 2-arachidonoyl glycerol, and their targets CB1Rs and CB2Rs appear to regulate seizure activity [113-120]. The rationale for the antiepileptic effects of the cannabinoid system contends that the CB1Rs (possibly also CB2Rs) are linked to inhibitory G-protein $\left(G_{i / o}\right)$ signaling, which reduces neuronal excitability and/or neural synchronization. For example, the activation of brain CB1Rs modulates A-type $\mathrm{K}^{+}$channels and N- and P/Qtype voltage-gated $\mathrm{Ca}^{2+}$ currents, which stabilizes membrane potentials [121, 122] and modulates presynaptic neurotransmitter release [123-125]. Based on these concepts, numerous cannabinoid analogs have been examined in a variety of animal models $[115,116,119,126-129]$. Although cannabinoid ligands and CB1R agonists possess some antiepileptic effects, nonspecific modulations of cannabinoid systems will limit their therapeutic use for the treatment of human epilepsy because of their severe adverse effects. Therefore, significant attention is currently being directed toward the possibility of developing medicines from compounds that can selectively activate CB2Rs and have important potential therapeutic applications at doses that induce little or no CB1R activity.

Emerging evidence has indicated that CB2Rs are involved in epileptic activity in animal models. In a rat model of acute pentylenetetrazole (PTZ)-induced seizure, pretreatment with palmitoylethanolamide (PEA) increased the latency of seizure initiation and reduced the duration of seizures. This antiepileptic effect was attenuated by either the CB1R (AM251) or CB2R (AM630) antagonists, suggesting that CB2R mediated PEA's effect [130]. In developing rats, Huizenga et al. examined the antiepileptic effects of a variety of cannabinoid ligands and found that CB1R/CB2R or selective CB1R agonists exhibited antiepileptic effects in 10-day-old rat models of either chemo-convulsing methyl-6,7-dimethoxy-4-ethyl-beta-carboline-3-carboxylate- or PTZ-induced seizure [131]. Although the CB2R-selective agonist HU308 did not show an antiepileptic effect, the CB2R-selective antagonist AM630 increased seizure severity [131]. In addition, a recent report showed that $C B 1 R$ knockout mice did not have an epilepsy phenotype, but co-KO CB1Rs and CB2Rs caused epilepsy in animals [132], suggesting that CB2Rs play a role in stabilizing the neuronal system. Overall, while manipulation of CB2Rs is a reasonable and promising rationale, the current data are still very limited, and the effects of CB2R ligands on human epilepsy have not been tested. New insights into the exact mechanism by which CB2R agonists modulate neural networks and how they control human seizure activity are needed to determine the efficacy of CB2Rs as a therapeutic target for epilepsy and the associated seizure activity. 


\section{THERAPEUTIC POTENTIAL OF CB2RS IN THE TREATMENT OF PAIN}

Pain is a ubiquitously unpleasant feeling among humans, as well as many animal species, often caused by actual and potential tissue damage. Opioids and nonsteroidal anti-inflammatory drugs have proven efficacious in the treatment of pain, but their use is significantly hampered due to serious adverse effects. A great need exists for the development of novel analgesics to control pain with long-term effectiveness [133]. Some studies have demonstrated that CB2Rs are redistributed in many important portions of pain pathways, such as DRG and afferent fibers in the dorsal horn of the spine, and may be upregulated under inflammatory and neuropathic pain conditions [134, 135]. In addition, it is being increasingly recognized that CB2Rs are located in neuronal circuits in the brain relevant for pain control and dopamine-mediated reward [32, 136]. These data provide an anatomical basis for the involvement of CB2Rs in the modulation of neuropathic pain.

Hyperalgesia and allodynia induced by sciatic nerve injury were enhanced in $\mathrm{CB}_{2} \mathrm{R}^{-/-}$mice, while a reduced manifestation of neuropathic pain was observed in transgenic mice overexpressing CB2Rs. Deletion of CB2Rs also contributed to the development of contralateral mirror image pain, associated with enhanced microglial and astrocytic activation in the contralateral spinal horn [137]. Recently, it has been shown that deletion of CB2Rs in DA neurons led to a significantly higher threshold for tail flick responses along with decreased, but insignificant, paw lick latency in the hot plate test [138]. There is an overwhelming body of convincing preclinical evidence demonstrating that CB2R agonists produce antinociceptive effects in laboratory animal models of pain [139-141]. Activation of CB2Rs by agonists inhibited sensory nerve activity, decreased the sensitization of the nerves and reduced these inflammatory mediators in animal models of acute and chronic pain, suggesting that CB2Rs are involved in the attenuation of inflammatory and neuropathic pain pathways $[138,139]$.

Tolerance and physical dependence are common complications of long-term treatment of pain with opioids. Glial cells became activated in response to opioids. This activation opposed opioid analgesia and enhanced both opioid tolerance and dependence. Conversely, the clinically relevant efficacy of opioids was improved in animal models by inhibition of glial activation or proinflammatory cytokine actions [142]. Previous studies have shown that CB2R expression is increased in microglia in different models of neuropathic pain [139]. CB2R activation stimulated the release of endogenous opioid beta-endorphin from keratinocytes, which in turn acted at opioid receptors on primary afferent neurons to inhibit nociception [143]. Treatment with CB2R agonists induced morphine analgesia and attenuated morphine tolerance, possibly via either decreasing proinflammatory mediators or inducing the expression of $\mu$-opioid receptors [144-146]. Thus, microglial CB2Rs may be a new target for preventing the development of opioid tolerance and may be highly efficacious in neuropathic pain states that are responsive to opioid analgesics. Given that the combination of selective CB2R agonists with conventional analgesics may lead to enhanced antinociception and reduce untoward side effects, therapeutics targeting CB2Rs hold promise as novel analgesics.

\section{CONCLUSIONS AND PERSPECTIVES}

In summary, the present review reveals that CB2Rs are expressed at low levels in specific brain areas of healthy individuals but are significantly upregulated in glial elements during most neurodegenerative disorders. This inducible feature allows CB2Rs to serve as diagnostic markers of neuroinflammation in the context of pathological conditions. Although the detailed mechanisms underlying the inducibility of CB2Rs are still unclear, the disease-

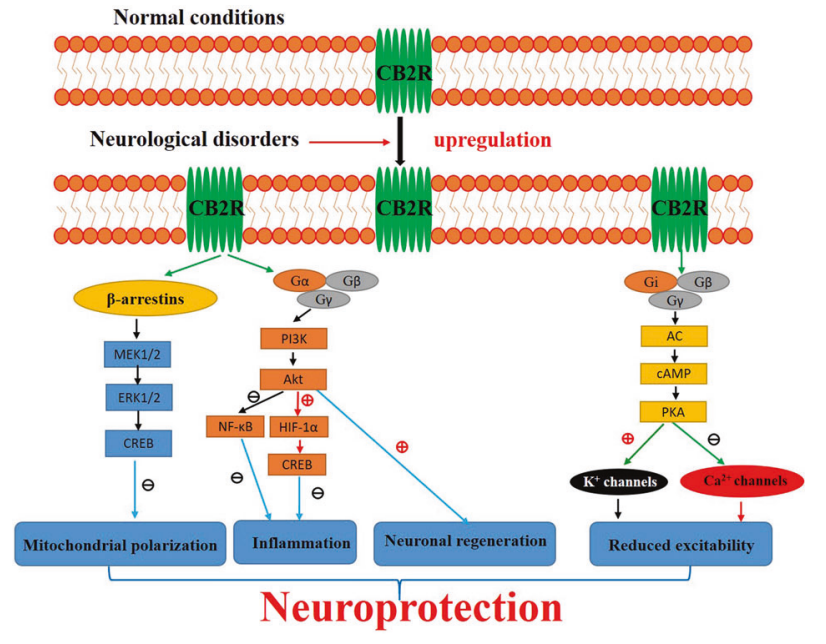

Fig. 1 Activation of CB2Rs after neurological disorders. Although brain CB2R levels are low in healthy individuals, they are significantly upregulated in glial elements in response to various neurological insults. Existing evidence demonstrates that signaling through CB2Rs can be mediated via $G$ protein and $\beta$-arrestin, each with their own downstream effectors [147-149]. As shown in Fig. 1, CB2Rs are coupled to Goi/o to inhibit adenylyl cyclase (AC) activity, leading to a decrease in cAMP levels. On the other hand, the $G \beta \gamma$ subunits, upon dissociation from Goi/o, are known to activate $\mathrm{G}$ protein-gated inwardly rectifying $\mathrm{K}^{+}$channels and $\mathrm{PI} 3 \mathrm{~K}$ and inhibit voltage-gated $\mathrm{Ca}^{2+}$ channels. Alternatively, $\beta$-arrestin 2 recruitment to CB2Rs results in activation of the ERK pathway. Overall, activation of CB2Rs plays neuroprotective roles, including attenuation of neuroinflammation, amelioration of mitochondrial depolarization and stimulation of neurogenesis, which could eventually reduce deficits in cognition, memory and motor inhibition. In addition, the activation of CB2Rs also modulates ion channel functions, thereby altering neuronal excitability, and leads to neuroprotection.

associated epigenetic modulations, CB2R promoter regulations, and transcription factors and their downstream cannabinoid receptor signaling, as well as cytokines, growth factors, hormones, and other factors released in response to tissue injury and inflammation, are rational starting points for further investigations of the inducible mechanisms. Moreover, a growing body of scientific literature has demonstrated that activation of CB2Rs suppresses neuroinflammation and prevents neuronal degeneration by a variety of mechanisms both in vitro and in vivo. At the same time, CB2R activation alters several ion channel functions, which, in turn, reduces neuronal excitability, leading to neuroprotection. Collectively, if proven therapeutic in clinical settings, selective CB2R activation may represent an avenue for the development of novel therapeutic agents that provide neuroprotection against a variety of neurological disorders (Fig. 1). On the other hand, the challenge of selectively targeting brain CB2Rs without affecting peripheral CB2Rs remains, as CB2R levels are much higher in peripheral tissues (e.g., T-cells in spleen) than in the brain. Thus, systemic exposure of CB2R ligands to activate brain CB2Rs will always activate peripheral CB2Rs. We have two thoughts regarding this challenge: (1) brain CB2Rs are strongly inducible, meaning that they are upregulated during disease conditions such as addiction, degeneration, and inflammation. This pathologyassociated increase significantly enhances the benefit to sideeffect ratio. (2) Activation of brain CB2Rs protects neurons against pathological conditions (e.g., addiction, anxiety, stroke, epilepsy), which additionally activates peripheral CB2Rs (e.g., Tcells), while peripheral CB2R activation will be beneficial to the central protective effect by reducing inflammation and immune responses. Therefore, the activation of peripheral CB2Rs may not 
induce side effects when brain CB2Rs are activated. Rather, both central and peripheral CB2Rs may work together to protect the brain's neurons against pathological alterations through neuronal and nonneuronal mechanisms.

\section{ACKNOWLEDGEMENTS}

We thank Dr. Jing Chen and Bai-liu Ya, at the Institute of Neurobiology in Jining Medical University, for their critical discussions and valuable comments for this article. The present work was supported by National Natural Science Foundation of China (81371437, 81703490), Shandong Province Medical and Health Technology Development Project (No. 2018WSB33004), Scientific Research Funds for young teachers of Jining Medical University (No. JYFC2019FKJ016), Research Fund for Academician Lin He New Medicine (JYHL2019MS17), Key Research and Development Project of Jining (2019SMNS018).

\section{AUTHOR CONTRIBUTIONS}

Both QX and FX equally contributed to writing the manuscript and sourcing references for the review. DHT and JFZ contributed to discussions and editing of the manuscript. JW conceived the outline of this paper and participated in critical review and further revision of the manuscript. All authors contributed to critical discussions and finalizing the manuscript before submission. They have all given approval to the final form of the manuscript.

\section{ADDITIONAL INFORMATION}

Competing interests: The authors declare no competing interests.

\section{REFERENCES}

1. Di Marzo V, Piscitelli F. The endocannabinoid system and its modulation by phytocannabinoids. Neurotherapeutics. 2015;12:692-8.

2. Huang WJ, Chen WW, Zhang X. Endocannabinoid system: role in depression, reward and pain control (Review). Mol Med Rep. 2016;14:2899-903.

3. Basavarajappa BS, Shivakumar M, Joshi V, Subbanna S. Endocannabinoid system in neurodegenerative disorders. J Neurochem. 2017;142:624-48.

4. Cristino L, Bisogno T, Di Marzo V. Cannabinoids and the expanded endocannabinoid system in neurological disorders. Nat Rev Neurol. 2020;16:9-29.

5. Nguyen T, Thomas BF, Zhang Y. Overcoming the psychiatric side effects of the cannabinoid CB1 receptor antagonists: current approaches for therapeutics development. Curr Top medicinal Chem. 2019;19:1418-35.

6. Moreira FA, Grieb M, Lutz B. Central side-effects of therapies based on CB1 cannabinoid receptor agonists and antagonists: focus on anxiety and depression. Best Pr Res Clin Endocrinol Metab. 2009;23:133-44.

7. Munro S, Thomas KL, Abu-Shaar M. Molecular characterization of a peripheral receptor for cannabinoids. Nature. 1993;365:61-5.

8. Galiegue S, Mary S, Marchand J, Dussossoy D, Carriere D, Carayon P, et al. Expression of central and peripheral cannabinoid receptors in human immune tissues and leukocyte subpopulations. Eur J Biochem. 1995;232:54-61.

9. Schatz AR, Lee M, Condie RB, Pulaski JT, Kaminski NE. Cannabinoid receptors CB1 and CB2: a characterization of expression and adenylate cyclase modulation within the immune system. Toxicol Appl Pharmacol. 1997;142:278-87.

10. McCoy KL, Matveyeva M, Carlisle SJ, Cabral GA. Cannabinoid inhibition of the processing of intact lysozyme by macrophages: evidence for CB2 receptor participation. J Pharmacol Exp Ther. 1999;289:1620-5.

11. Burdyga G, Lal S, Varro A, Dimaline R, Thompson DG, Dockray GJ. Expression of cannabinoid $\mathrm{CB} 1$ receptors by vagal afferent neurons is inhibited by cholecystokinin. J Neurosci. 2004;24:2708-15.

12. Atwood BK, Mackie K. CB2: a cannabinoid receptor with an identity crisis. Br J Pharmacol. 2010;160:467-79.

13. Jordan CJ, Xi ZX. Progress in brain cannabinoid CB2 receptor research: From genes to behavior. Neurosci Biobehav Rev. 2019;98:208-20.

14. Reddy V, Grogan D, Ahluwalia M, Salles EL, Ahluwalia P, Khodadadi H, et al. Targeting the endocannabinoid system: a predictive, preventive, and personalized medicine-directed approach to the management of brain pathologies. EPMA J. 2020;11:217-50.

15. Miller LK, Devi LA. The highs and lows of cannabinoid receptor expression in disease: mechanisms and their therapeutic implications. Pharmacol Rev. 2011;63:461-70

16. Onaivi ES, Ishiguro $H$, Gong JP, Patel S, Meozzi PA, Myers L, et al. Functional expression of brain neuronal $\mathrm{CB} 2$ cannabinoid receptors are involved in the effects of drugs of abuse and in depression. Ann N Y Acad Sci. 2008;1139: 434-49.

17. Onaivi ES, Ishiguro $H, G u S$, Liu QR. CNS effects of CB2 cannabinoid receptors: beyond neuro-immuno-cannabinoid activity. J Psychopharmacol. 2012;26: 92-103.

18. Pacher $P$, Mechoulam R. Is lipid signaling through cannabinoid 2 receptors part of a protective system? Prog Lipid Res. 2011;50:193-211.

19. Fernandez-Ruiz J, Pazos MR, Garcia-Arencibia M, Sagredo O, Ramos JA. Role of $\mathrm{CB} 2$ receptors in neuroprotective effects of cannabinoids. Mol Cell Endocrinol. 2008;286:S91-6.

20. Hryhorowicz S, Kaczmarek-Rys M, Andrzejewska A, Staszak K, Hryhorowicz M, Korcz A, et al. Allosteric modulation of cannabinoid receptor 1-current challenges and future opportunities. Int J Mol Sci. 2019;20:5874.

21. Xi ZX, Peng XQ, Li X, Song R, Zhang HY, Liu QR, et al. Brain cannabinoid $C B(2)$ receptors modulate cocaine's actions in mice. Nat Neurosci. 2011;14:1160-6.

22. Navarrete F, Rodriguez-Arias M, Martin-Garcia E, Navarro D, Garcia-Gutierrez MS, Aguilar MA, et al. Role of $C B 2$ cannabinoid receptors in the rewarding, reinforcing, and physical effects of nicotine. Neuropsychopharmacology. 2013;38:2515-24.

23. Ortega-Álvaro A, Ternianov A, Aracil-Fernández A, Navarrete F, García-Gutiérrez MS, Manzanares J. Role of cannabinoid CB receptor in the reinforcing actions of ethanol. Addict Biol 2013;20:43-55.

24. Pertwee RG. Targeting the endocannabinoid system with cannabinoid receptor agonists: pharmacological strategies and therapeutic possibilities. Philos Trans $R$ Soc Lond B Biol Sci. 2012;367:3353-63.

25. Gong JP, Onaivi ES, Ishiguro H, Liu QR, Tagliaferro PA, Brusco A, et al. Cannabinoid $C B 2$ receptors: immunohistochemical localization in rat brain. Brain Res. 2006;1071:10-23.

26. Brusco A, Tagliaferro PA, Saez T, Onaivi ES. Ultrastructural localization of neuronal brain CB2 cannabinoid receptors. Ann N Y Acad Sci. 2008;1139:450-7.

27. Ashton JC, Friberg D, Darlington CL, Smith PF. Expression of the cannabinoid CB2 receptor in the rat cerebellum: an immunohistochemical study. Neurosci Lett. 2006;396:113-6.

28. Baek JH, Zheng Y, Darlington CL, Smith PF. Cannabinoid CB2 receptor expression in the rat brainstem cochlear and vestibular nuclei. Acta Otolaryngol. 2008;128:961-7.

29. Brusco A, Tagliaferro P, Saez T, Onaivi ES. Postsynaptic localization of CB2 cannabinoid receptors in the rat hippocampus. Synapse. 2008;62:944-9.

30. Van Sickle MD, Duncan M, Kingsley PJ, Mouihate A, Urbani $P$, Mackie K, et al. Identification and functional characterization of brainstem cannabinoid CB2 receptors. Science. 2005;310:329-32.

31. Núñez E, Benito $C$, Pazos MR, Barbachano A, Fajardo O, González $S$, et al. Cannabinoid $C B 2$ receptors are expressed by perivascular microglial cells in the human brain: an immunohistochemical study. Synapse. 2004;53:208-13.

32. Zhang HY, Gao M, Liu QR, Bi GH, Li X, Yang HJ, et al. Cannabinoid CB2 receptors modulate midbrain dopamine neuronal activity and dopamine-related behavior in mice. Proc Natl Acad Sci U S A. 2014;111:E5007-15.

33. Stempel AV, Stumpf A, Zhang HY, Ozdogan T, Pannasch U, Theis AK, et al. Cannabinoid type 2 receptors mediate a cell type-specific plasticity in the hippocampus. Neuron. 2016;90:795-809.

34. Joshi N, Onaivi ES. Endocannabinoid system components: overview and tissue distribution. Adv Exp Med Biol. 2019;1162:1-12.

35. Liu QR, Pan CH, Hishimoto A, Li CY, Xi ZX, Llorente-Berzal A, et al. Species differences in cannabinoid receptor 2 (CNR2 gene): identification of novel human and rodent CB2 isoforms, differential tissue expression and regulation by cannabinoid receptor ligands. Genes Brain Behav. 2009;8:519-30.

36. Maccarone R, Rapino C, Zerti D, di Tommaso M, Battista N, Di Marco S, et al. Modulation of type- 1 and type- 2 cannabinoid receptors by saffron in a rat model of retinal neurodegeneration. PLoS ONE. 2016;11:e0166827.

37. Zhang HY, Bi GH, Li X, Li J, Qu H, Zhang SJ, et al. Species differences in cannabinoid receptor 2 and receptor responses to cocaine self-administration in mice and rats. Neuropsychopharmacology. 2015;40:1037-51.

38. Li Y, Kim J. Neuronal expression of CB2 cannabinoid receptor mRNAs in the mouse hippocampus. Neuroscience. 2015;311:253-67.

39. Gómez-Gálvez Y, Palomo-Garo C, Fernández-Ruiz J, García C. Potential of the cannabinoid $\mathrm{CB}(2)$ receptor as a pharmacological target against inflammation in Parkinson's disease. Prog Neuropsychopharmacol Biol Psychiatry. 2016;64: 200-8.

40. Chung YC, Shin WH, Baek JY, Cho EJ, Baik HH, Kim SR, et al. CB2 receptor activation prevents glial-derived neurotoxic mediator production, BBB leakage and peripheral immune cell infiltration and rescues dopamine neurons in the MPTP model of Parkinson's disease. Exp Mol Med. 2016;48:e205.

41. Lu Q, Straiker A, Maguire G. Expression of CB2 cannabinoid receptor mRNA in adult rat retina. Vis Neurosci. 2000;17:91-5. 
42. Palazuelos J, Ortega Z, Díaz-Alonso J, Guzmán M, Galve-Roperh I. CB2 cannabinoid receptors promote neural progenitor cell proliferation via mTORC1 signaling. J Biol Chem. 2012;287:1198-209.

43. Benjamin EJ, Virani SS, Callaway CW, Chamberlain AM, Chang AR, Cheng S, et al. Heart disease and stroke statistics-2018 update: a report from the American Heart Association. Circulation. 2018;137:e67-e492.

44. Webb RL, Kaiser EE, Jurgielewicz BJ, Spellicy S, Scoville SL, Thompson TA, et al. Human neural stem cell extracellular vesicles improve recovery in a porcine model of ischemic stroke. Stroke. 2018;49:1248-56.

45. Hosoya T, Fukumoto D, Kakiuchi T, Nishiyama S, Yamamoto S, Ohba H, et al. In vivo TSPO and cannabinoid receptor type 2 availability early in post-stroke neuroinflammation in rats: a positron emission tomography study. J Neuroinflammation. 2017:14:69.

46. Zhang M, Martin BR, Adler MW, Razdan RK, Jallo Jl, Tuma RF, et al. Cannabinoid $\mathrm{CB}(2)$ receptor activation decreases cerebral infarction in a mouse focal ischemia/reperfusion model. J Cereb Blood Flow Metab. 2007;27:1387-96.

47. Zhang M, Adler MW, Abood ME, Ganea D, Jallo J, Tuma RF. CB2 receptor activation attenuates microcirculatory dysfunction during cerebral ischemic/reperfusion injury. Microvasc Res. 2009;78:86-94.

48. Murikinati S, Juttler E, Keinert T, Ridder DA, Muhammad S, Waibler Z, et al. Activation of cannabinoid 2 receptors protects against cerebral ischemia by inhibiting neutrophil recruitment. FASEB J. 2010;24:788-98.

49. Choi IY, Ju C, Anthony Jalin AM, Lee DI, Prather PL, Kim WK. Activation of cannabinoid CB2 receptor-mediated AMPK/CREB pathway reduces cerebral ischemic injury. Am J Pathol. 2013;182:928-39.

50. Guo K, Mou X, Huang J, Xiong N, Li H. Trans-caryophyllene suppresses hypoxiainduced neuroinflammatory responses by inhibiting NF-kappaB activation in microglia. J Mol Neurosci. 2014;54:41-8.

51. Cheng L, Li J, Zhou Y, Zheng Q, Ming X, Liu S. N-linoleyltyrosine protects against transient cerebral ischemia in gerbil via CB2 receptor involvement in PI3K/Akt signaling pathway. Biol Pharm Bull. 2019;42:1867-76.

52. Yu SJ, Reiner D, Shen H, Wu KJ, Liu QR, Wang Y. Time-Dependent Protection of CB2 Receptor Agonist in Stroke. PLoS ONE. 2015;10:e0132487.

53. Ronca RD, Myers AM, Ganea D, Tuma RF, Walker EA, Ward SJ. A selective cannabinoid CB2 agonist attenuates damage and improves memory retention following stroke in mice. Life Sci. 2015;138:72-7.

54. Kossatz E, Maldonado R, Robledo P. CB2 cannabinoid receptors modulate HIF1alpha and TIM-3 expression in a hypoxia-ischemia mouse model. Eur Neuropsychopharmacol. 2016;26:1972-88.

55. Bravo-Ferrer I, Cuartero MI, Zarruk JG, Pradillo JM, Hurtado O, Romera VG, et al. Cannabinoid type-2 receptor drives neurogenesis and improves functional outcome after stroke. Stroke. 2017;48:204-12.

56. Ahmad A, Ali T, Park HY, Badshah H, Rehman SU, Kim MO. Neuroprotective effect of fisetin against amyloid-beta-induced cognitive/synaptic dysfunction, neuroinflammation, and neurodegeneration in adult mice. Mol Neurobiol. 2017:54:2269-85.

57. Lopez A, Aparicio N, Pazos MR, Grande MT, Barreda-Manso MA, Benito-Cuesta I, et al. Cannabinoid CB2 receptors in the mouse brain: relevance for Alzheimer's disease. J Neuroinflammation. 2018;15:158.

58. Schmöle AC, Lundt R, Toporowski G, Hansen JN, Beins E, Halle A, et al. Cannabinoid receptor 2-deficiency ameliorates disease symptoms in a mouse model with Alzheimer's disease-like pathology. J Alzheimers Dis. 2018;64:379-92.

59. Benito C, Nunez E, Tolon RM, Carrier EJ, Rabano A, Hillard CJ, et al. Cannabinoid $C B 2$ receptors and fatty acid amide hydrolase are selectively overexpressed in neuritic plaque-associated glia in Alzheimer's disease brains. J Neurosci. 2003;23:11136-41.

60. Ramirez BG, Blazquez C, Gomez del Pulgar T, Guzman M, de Ceballos ML. Prevention of Alzheimer's disease pathology by cannabinoids: neuroprotection mediated by blockade of microglial activation. J Neurosci. 2005;25:1904-13.

61. Solas M, Francis PT, Franco R, Ramirez MJ. CB2 receptor and amyloid pathology in frontal cortex of Alzheimer's disease patients. Neurobiol Aging. 2013;34:805-8.

62. Savonenko AV, Melnikova T, Wang Y, Ravert H, Gao Y, Koppel J, et al. Cannabinoid $C B 2$ receptors in a mouse model of abeta amyloidosis: immunohistochemical analysis and suitability as a PET biomarker of neuroinflammation. PLoS ONE. 2015;10:e0129618.

63. Koppel J, Vingtdeux V, Marambaud P, d'Abramo C, Jimenez H, Stauber M, et al. CB2 receptor deficiency increases amyloid pathology and alters tau processing in a transgenic mouse model of Alzheimer's disease. Mol Med. 2014;20:29-36.

64. Klegeris A, Bissonnette CJ, McGeer PL. Reduction of human monocytic cell neurotoxicity and cytokine secretion by ligands of the cannabinoid-type $\mathrm{CB} 2$ receptor. Br J Pharmacol. 2003;139:775-86.

65. Aso $\mathrm{E}$, Juves $\mathrm{S}$, Maldonado R, Ferrer I. CB2 cannabinoid receptor agonist ameliorates Alzheimer-like phenotype in AbetaPP/PS1 mice. J Alzheimers Dis. 2013:35:847-58.
66. Navarro-Dorado J, Villalba N, Prieto D, Brera B, Martín-Moreno AM, Tejerina T, et al. Vascular dysfunction in a transgenic model of Alzheimer's disease: effects of CB1R and CB2R cannabinoid agonists. Front Neurosci. 2016;10:422.

67. Wu J, Bie B, Yang H, Xu JJ, Brown DL, Naguib M. Activation of the CB2 receptor system reverses amyloid-induced memory deficiency. Neurobiol Aging. 2013;34:791-804.

68. Wu J, Hocevar M, Foss JF, Bie B, Naguib M. Activation of CB2 receptor system restores cognitive capacity and hippocampal Sox2 expression in a transgenic mouse model of Alzheimer's disease. Eur J Pharmacol. 2017;811:12-20.

69. Kofalvi A, Lemos C, Martin-Moreno AM, Pinheiro BS, Garcia-Garcia L, Pozo MA, et al. Stimulation of brain glucose uptake by cannabinoid $C B 2$ receptors and its therapeutic potential in Alzheimer's disease. Neuropharmacology. 2016;110:519-29.

70. Li C, Shi J, Wang B, Li J, Jia H. CB2 cannabinoid receptor agonist ameliorates novel object recognition but not spatial memory in transgenic APP/PS1 mice. Neurosci Lett. 2019;707:134286.

71. Zhang J, Chen C. Alleviation of neuropathology by inhibition of monoacylglycerol lipase in APP transgenic mice lacking CB2 receptors. Mol Neurobiol. 2018;55:4802-10.

72. Chen R, Zhang J, Wu Y, Wang D, Feng G, Tang YP, et al. Monoacylglycerol lipase is a therapeutic target for Alzheimer's disease. Cell Rep. 2012;2:1329-39.

73. Aso E, Andrés-Benito P, Carmona M, Maldonado R, Ferrer I. Cannabinoid receptor 2 participates in amyloid- $\beta$ processing in a mouse model of Alzheimer's disease but plays a minor role in the therapeutic properties of a cannabis-based medicine. J Alzheimers Dis. 2016;51:489-500.

74. Schmöle AC, Lundt R, Ternes S, Albayram Ö, Ulas T, Schultze JL, et al. Cannabinoid receptor 2 deficiency results in reduced neuroinflammation in an Alzheimer's disease mouse model. Neurobiol Aging. 2015;36:710-9.

75. Mhyre TR, Boyd JT, Hamill RW, Maguire-Zeiss KA. Parkinson's disease. Sub-Cell Biochem. 2012;65:389-455.

76. Concannon RM, Okine BN, Finn DP, Dowd E. Differential upregulation of the cannabinoid $\mathrm{CB}(2)$ receptor in neurotoxic and inflammation-driven rat models of Parkinson's disease. Exp Neurol. 2015;269:133-41.

77. García MC, Cinquina V, Palomo-Garo C, Rábano A, Fernández-Ruiz J. Identification of $\mathrm{CB}_{2}$ receptors in human nigral neurons that degenerate in Parkinson's disease. Neurosci Lett. 2015;587:1-4.

78. Shi J, Cai Q, Zhang J, He X, Liu Y, Zhu R, et al. AM1241 alleviates MPTP-induced Parkinson's disease and promotes the regeneration of DA neurons in PD mice. Oncotarget. 2017;8:67837-50.

79. Price DA, Martinez AA, Seillier A, Koek W, Acosta $Y$, Fernandez $E$, et al. WIN55,212-2, a cannabinoid receptor agonist, protects against nigrostriatal cell loss in the 1-methyl-4-phenyl-1,2,3,6-tetrahydropyridine mouse model of Parkinson's disease. Eur J Neurosci. 2009;29:2177-86.

80. Javed H, Azimullah S, Haque ME, Ojha SK. Cannabinoid type 2 (CB2) receptors activation protects against oxidative stress and neuroinflammation associated dopaminergic neurodegeneration in rotenone model of Parkinson's disease. Front Neurosci. 2016;10:321.

81. Viveros-Paredes JM, Gonzalez-Castaneda RE, Gertsch J, Chaparro-Huerta V, Lopez-Roa Rl, Vazquez-Valls $\mathrm{E}$, et al. Neuroprotective effects of betacaryophyllene against dopaminergic neuron injury in a murine model of parkinson's disease induced by MPTP. Pharmaceuticals (Basel, Switz). 2017;10:60.

82. Wang G, Ma W, Du J. beta-Caryophyllene (BCP) ameliorates MPP+ induced cytotoxicity. Biomed Pharmacother. 2018;103:1086-91.

83. Eddings CR, Arbez N, Akimov S, Geva M, Hayden MR, Ross CA. Pridopidine protects neurons from mutant-huntingtin toxicity via the sigma-1 receptor. Neurobiol Dis. 2019:129:118-29.

84. Spinelli F, Capparelli E, Abate C, Colabufo NA, Contino M. Perspectives of Cannabinoid type 2 receptor (CB2R) ligands in neurodegenerative disorders: structure-affinity relationship (SAfiR) and structure-activity relationship (SAR) studies. J Med Chem. 2017;60:9913-31.

85. Haider A, Spinelli F, Herde AM, Mu B, Keller C, Margelisch M, et al. Evaluation of 4-oxo-quinoline-based CB2 PET radioligands in R6/2 chorea huntington mouse model and human ALS spinal cord tissue. Eur J Med Chem. 2018;145:746-59.

86. Palazuelos J, Aguado T, Pazos MR, Julien B, Carrasco C, Resel E, et al. Microglial CB2 cannabinoid receptors are neuroprotective in Huntington's disease excitotoxicity. Brain. 2009;132:3152-64.

87. Sagredo O, Gonzalez S, Aroyo I, Pazos MR, Benito C, Lastres-Becker I, et al. Cannabinoid $C B 2$ receptor agonists protect the striatum against malonate toxicity: relevance for Huntington's disease. Glia. 2009;57:1154-67.

88. Bouchard J, Truong J, Bouchard K, Dunkelberger D, Desrayaud S, Moussaoui S, et al. Cannabinoid receptor 2 signaling in peripheral immune cells modulates disease onset and severity in mouse models of Huntington's disease. J Neurosci. 2012;32:18259-68.

89. Dowie MJ, Grimsey NL, Hoffman T, Faull RL, Glass M. Cannabinoid receptor CB2 is expressed on vascular cells, but not astroglial cells in the post-mortem human Huntington's disease brain. J Chem Neuroanat. 2014;59-60:62-71. 
90. Jafarzadeh Bejargafshe M, Hedayati M, Zahabiasli S, Tahmasbpour E, Rahmanzadeh S, Nejad-Moghaddam A. Safety and efficacy of stem cell therapy for treatment of neural damage in patients with multiple sclerosis. Stem Cell Investig. 2019;6:44.

91. Gonçalves ED, Dutra RC. Cannabinoid receptors as therapeutic targets for autoimmune diseases: where do we stand? Drug Disco Today. 2019;24:1845-53.

92. Tahamtan A, Rezaiy S, Samadizadeh S, Moradi A, Tabarraei A, Javid N, et al. Cannabinoid CB2 receptor functional variation (Q63R) is associated with multiple sclerosis in iranian subjects. J Mol Neurosci. 2020;70:26-31.

93. Maresz K, Carrier EJ, Ponomarev ED, Hillard CJ, Dittel BN. Modulation of the cannabinoid CB2 receptor in microglial cells in response to inflammatory stimuli. J Neurochem. 2005;95:437-45.

94. Yiangou $Y$, Facer $P$, Durrenberger $P$, Chessell IP, Naylor A, Bountra $C$, et al. COX-2, CB2 and P2X7-immunoreactivities are increased in activated microglial cells/ macrophages of multiple sclerosis and amyotrophic lateral sclerosis spinal cord. BMC Neurol. 2006;6:12.

95. Benito C, Romero JP, Tolon RM, Clemente D, Docagne F, Hillard CJ, et al. Cannabinoid $C B 1$ and $C B 2$ receptors and fatty acid amide hydrolase are specific markers of plaque cell subtypes in human multiple sclerosis. J Neurosci. 2007;27:2396-402.

96. Palazuelos J, Davoust N, Julien B, Hatterer E, Aguado T, Mechoulam R, et al. The $\mathrm{CB}(2)$ cannabinoid receptor controls myeloid progenitor trafficking: involvement in the pathogenesis of an animal model of multiple sclerosis. J Biol Chem. 2008;283:13320-9.

97. Zhang M, Martin BR, Adler MW, Razdan RJ, Kong W, Ganea D, et al. Modulation of cannabinoid receptor activation as a neuroprotective strategy for EAE and stroke. J Neurolmmune Pharmacol. 2009;4:249-59.

98. Lourbopoulos A, Grigoriadis N, Lagoudaki R, Touloumi O, Polyzoidou E, Mavromatis $\mathrm{I}$, et al. Administration of 2-arachidonoylglycerol ameliorates both acute and chronic experimental autoimmune encephalomyelitis. Brain Res. 2011;1390: 126-41.

99. Correa F, Docagne F, Mestre L, Clemente D, Hernangomez M, Loria F, et al. A role for $\mathrm{CB} 2$ receptors in anandamide signalling pathways involved in the regulation of IL-12 and IL-23 in microglial cells. Biochem Pharmacol. 2009;77:86-100.

100. Fu W, Taylor BK. Activation of cannabinoid CB2 receptors reduces hyperalgesia in an experimental autoimmune encephalomyelitis mouse model of multiple sclerosis. Neurosci Lett. 2015;595:1-6.

101. Alberti TB, Barbosa WL, Vieira JL, Raposo NR, Dutra RC. (-)- $\beta$-Caryophyllene, a CB2 receptor-selective phytocannabinoid, suppresses motor paralysis and neuroinflammation in a murine model of multiple sclerosis. Int J Mol Sci. 2017;18:691.

102. Sirabella R, Valsecchi V, Anzilotti S, Cuomo O, Vinciguerra A, Cepparulo $P$, et al. lonic homeostasis maintenance in ALS: focus on new therapeutic targets. Front Neurosci. 2018;12:510.

103. Habib AA, Mitsumoto $H$. Emerging drugs for amyotrophic lateral sclerosis. Expert Opin Emerg Drugs. 2011;16:537-58.

104. Shoemaker JL, Seely KA, Reed RL, Crow JP, Prather PL. The CB2 cannabinoid agonist AM-1241 prolongs survival in a transgenic mouse model of amyotrophic lateral sclerosis when initiated at symptom onset. J Neurochem. 2007;101:87-98

105. Kim K, Moore DH, Makriyannis A, Abood ME. AM1241, a cannabinoid CB2 receptor selective compound, delays disease progression in a mouse model of amyotrophic lateral sclerosis. Eur J Pharmacol. 2006;542:100-5.

106. Espejo-Porras F, García-Toscano L, Rodríguez-Cueto C, Santos-García I, de Lago E, Fernandez-Ruiz J. Targeting glial cannabinoid CB. Br J Pharmacol. 2019;176: 1585-600.

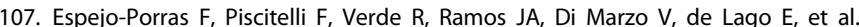
Changes in the endocannabinoid signaling system in CNS structures of TDP-43 transgenic mice: relevance for a neuroprotective therapy in TDP-43-related disorders. J Neuroimmune Pharmacol. 2015;10:233-44.

108. Fernández-Trapero $M$, Espejo-Porras $F$, Rodríguez-Cueto $C$, Coates JR, Pérez-Díaz $C$, de Lago $E$, et al. Upregulation of $\mathrm{CB}_{2}$ receptors in reactive astrocytes in canine degenerative myelopathy, a disease model of amyotrophic lateral sclerosis. Dis Model Mech. 2017;10:551-8.

109. Espejo-Porras F, Fernández-Ruiz J, de Lago E. Analysis of endocannabinoid receptors and enzymes in the post-mortem motor cortex and spinal cord of amyotrophic lateral sclerosis patients. Amyotroph Lateral Scler Frontotemporal Degener. 2018;19:377-86.

110. Mu L, Bieri D, Slavik R, Drandarov K, Müller A, Cermak S, et al. Radiolabeling and in vitro /in vivo evaluation of $\mathrm{N}$-(1-adamantyl)-8-methoxy-4-oxo-1-phenyl-1,4dihydroquinoline-3-carboxamide as a PET probe for imaging cannabinoid type 2 receptor. J Neurochem. 2013;126:616-24.

111. Wei F, Yan LM, Su T, He N, Lin ZJ, Wang J, et al. lon channel genes and epilepsy: functional alteration, pathogenic potential, and mechanism of epilepsy. Neurosci Bull. 2017:33:455-77.
112. Tang F, Hartz AMS, Bauer B. Drug-resistant epilepsy: multiple hypotheses, few answers. Front Neurol. 2017:8:301.

113. Deshpande LS, Sombati S, Blair RE, Carter DS, Martin BR, DeLorenzo RJ. Cannabinoid CB1 receptor antagonists cause status epilepticus-like activity in the hippocampal neuronal culture model of acquired epilepsy. Neurosci Lett. 2007;411:11-6.

114. Kozan R, Ayyildiz M, Agar E. The effects of intracerebroventricular AM-251, a CB1-receptor antagonist, and ACEA, a CB1-receptor agonist, on penicillininduced epileptiform activity in rats. Epilepsia. 2009;50:1760-7.

115. Cakil D, Yildirim M, Ayyildiz M, Agar E. The effect of co-administration of the NMDA blocker with agonist and antagonist of CB1-receptor on penicillininduced epileptiform activity in rats. Epilepsy Res. 2011;93:128-37.

116. Wallace MJ, Blair RE, Falenski KW, Martin BR, DeLorenzo RJ. The endogenous cannabinoid system regulates seizure frequency and duration in a model of temporal lobe epilepsy. J Pharmacol Exp Ther. 2003;307:129-37.

117. Capasso A. Do Cannabinoids confer neuroprotection against epilepsy? An overview. Open Neurol J. 2017;11:61-73.

118. Neale M. Efficacy and safety of cannabis for treating children with refractory epilepsy. Nurs Child Young People. 2017;29:32-7.

119. De Caro C, Leo A, Citraro R, De Sarro C, Russo R, Calignano A, et al. The potential role of cannabinoids in epilepsy treatment. Expert Rev Neurother. 2017;17: 1069-79.

120. Sugaya $Y$, Yamazaki M, Uchigashima M, Kobayashi K, Watanabe M, Sakimura K, et al. Crucial roles of the endocannabinoid 2-arachidonoylglycerol in the suppression of epileptic seizures. Cell Rep. 2016;16:1405-15.

121. Deadwyler SA, Hampson RE, Mu J, Whyte A, Childers S. Cannabinoids modulate voltage sensitive potassium A-current in hippocampal neurons via a cAMPdependent process. J Pharmacol Exp Ther. 1995;273:734-43.

122. Pan X, Ikeda SR, Lewis DL. Rat brain cannabinoid receptor modulates N-type Ca2+ channels in a neuronal expression system. Mol Pharmacol. 1996;49: 707-14.

123. Kreitzer AC, Regehr WG. Retrograde inhibition of presynaptic calcium influx by endogenous cannabinoids at excitatory synapses onto Purkinje cells. Neuron. 2001;29:717-27.

124. Wilson RI, Nicoll RA. Endogenous cannabinoids mediate retrograde signalling at hippocampal synapses. Nature. 2001;410:588-92.

125. Wilson RI, Kunos G, Nicoll RA. Presynaptic specificity of endocannabinoid signaling in the hippocampus. Neuron. 2001;31:453-62.

126. Arslan G, Ayyildiz M, Agar E. The interaction between ghrelin and cannabinoid systems in penicillin-induced epileptiform activity in rats. Neuropeptides. 2014;48:345-52.

127. Devinsky O, Marsh E, Friedman D, Thiele E, Laux L, Sullivan J, et al. Cannabidiol in patients with treatment-resistant epilepsy: an open-label interventional trial. Lancet Neurol. 2016;15:270-8.

128. Devinsky O, Cross JH, Wright S. Trial of cannabidiol for drug-resistant seizures in the Dravet syndrome. N Engl J Med. 2017;377:699-700.

129. Szaflarski M, Hansen B, Bebin EM, Szaflarski JP. Social correlates of health status, quality of life, and mood states in patients treated with cannabidiol for epilepsy. Epilepsy Behav. 2017;70:364-9.

130. Aghaei I, Rostampour M, Shabani M, Naderi N, Motamedi F, Babaei $P$, et al. Palmitoylethanolamide attenuates PTZ-induced seizures through $\mathrm{CB} 1$ and $\mathrm{CB} 2$ receptors. Epilepsy Res. 2015;117:23-8.

131. Huizenga MN, Wicker E, Beck VC, Forcelli PA. Anticonvulsant effect of cannabinoid receptor agonists in models of seizures in developing rats. Epilepsia. 2017;58:1593-602.

132. Rowley S, Sun X, Lima IV, Tavenier A, de Oliveira ACP, Dey SK, et al. Cannabinoid receptor $1 / 2$ double-knockout mice develop epilepsy. Epilepsia. 2017;58: e162-e6.

133. Xin Q, Bai B, Liu W. The analgesic effects of oxytocin in the peripheral and central nervous system. Neurochem Int. 2017;103:57-64.

134. Guerrero-Alba R, Barragan-Iglesias P, Gonzalez-Hernandez A, Valdez-Morales EE, Granados-Soto V, Condes-Lara $M$, et al. Some prospective alternatives for treating pain: the endocannabinoid system and its putative receptors GPR18 and GPR55. Front Pharmacol. 2018;9:1496.

135. Svizenska IH, Brazda V, Klusakova I, Dubovy P. Bilateral changes of cannabinoid receptor type 2 protein and mRNA in the dorsal root ganglia of a rat neuropathic pain model. J Histochem Cytochem. 2013;61:529-47.

136. Lotsch J, Weyer-Menkhoff I, Tegeder I. Current evidence of cannabinoid-based analgesia obtained in preclinical and human experimental settings. Eur J Pain. 2018;22:471-84

137. Racz I, Nadal X, Alferink J, Banos JE, Rehnelt J, Martin M, et al. Crucial role of CB2 cannabinoid receptor in the regulation of central immune responses during neuropathic pain. J Neurosci. 2008;28:12125-35.

138. Liu QR, Canseco-Alba A, Zhang HY, Tagliaferro P, Chung M, Dennis E, et al. Cannabinoid type 2 receptors in dopamine neurons inhibits psychomotor 
behaviors, alters anxiety, depression and alcohol preference. Sci Rep. 2017;7:17410.

139. Hossain MZ, Ando H, Unno S, Kitagawa J. Targeting peripherally restricted cannabinoid receptor 1, cannabinoid receptor 2, and endocannabinoiddegrading enzymes for the treatment of neuropathic pain including neuropathic orofacial pain. Int J Mol Sci. 2020;21:1423.

140. Sanchez-Aparicio P, Floran B, Velazquez DR, Ibancovichi JA, Guerrero JAV, Recillas $S$. Cannabinoids CB2 receptors, one new promising drug target for chronic and degenerative pain conditions in equine veterinary patients. J Equine Vet Sci. 2020;85:102880.

141. Deng LT, Guindon J, Cornett BL, Makriyannis A, Mackie K, Hohmann AG. Chronic cannabinoid receptor 2 Activation reverses paclitaxel neuropathy without tolerance or cannabinoid receptor 1-dependent withdrawal. Biol Psychiatry. 2015;77:475-87.

142. Watkins LR, Hutchinson MR, Rice KC, Maier SF. The "toll" of opioid-induced glial activation: improving the clinical efficacy of opioids by targeting glia. Trends Pharmacol Sci. 2009;30:581-91.

143. Ibrahim MM, Porreca F, Lai J, Albrecht PJ, Rice FL, Khodorova A, et al. CB2 cannabinoid receptor activation produces antinociception by stimulating peripheral release of endogenous opioids. Proc Natl Acad Sci USA. 2005;102:3093-8.

144. Li AL, Lin XY, Dhopeshwarkar AS, Thomaz AC, Carey LM, Liu YP, et al. Cannabinoid $C B 2$ agonist AM1710 differentially suppresses distinct pathological pain states and attenuates morphine tolerance and withdrawal. Mol Pharmacol. 2019;95:155-68.

145. Lin XY, Dhopeshwarkar AS, Huibregtse M, Mackie K, Hohmann AG. Slowly signaling $G$ protein-biased CB2 cannabinoid receptor agonist LY2828360 suppresses neuropathic pain with sustained efficacy and attenuates morphine tolerance and dependence. Mol Pharmacol. 2018;93:49-62.
146. Zhang MY, Wang K, Ma M, Tian SY, Wei N, Wang GN. Low-dose cannabinoid type 2 receptor agonist attenuates tolerance to repeated morphine administration via regulating mu-opioid receptor expression in walker 256 tumorbearing rats. Anesth Analg. 2016;122:1031-7.

147. Wouters E, Walraed J, Banister SD, Stove CP. Insights into biased signaling at cannabinoid receptors: synthetic cannabinoid receptor agonists. Biochem Pharmacol. 2019;169:113623.

148. Ye L, Cao Z, Wang W, Zhou N. New insights in cannabinoid receptor structure and signaling. Curr Mol Pharmacol. 2019;12:239-48.

149. An D, Peigneur S, Hendrickx LA, Tytgat J. Targeting cannabinoid receptors: current status and prospects of natural products. Int J Mol Sci. 2020;21:5064.

150. Cécyre B, Zabouri N, Huppé-Gourgues F, Bouchard JF, Casanova C. Roles of cannabinoid receptors type 1 and 2 on the retinal function of adult mice. Invest Ophthalmol Vis Sci. 2013;54:8079.

151. Yang W, Li Q, Wang SY, Gao F, Qian WJ, Li F, et al. Cannabinoid receptor agonists modulate calcium channels in rat retinal müller cells. Neuroscience. 2016;313: 213-24.

152. Bouskila J, Javadi P, Casanova C, Ptito M, Bouchard JF. Müller cells express the cannabinoid CB2 receptor in the vervet monkey retina. J Comp Neurol. 2013;521:2399-415.

153. Lanciego JL, Barroso-Chinea P, Rico AJ, Conte-Perales L, Callén L, Roda E, et al. Expression of the mRNA coding the cannabinoid receptor 2 in the pallidal complex of. J Psychopharmacol. 2020;25:97-104.

154. Sierra S, Luquin N, Rico AJ, Gómez-Bautista V, Roda E, Dopeso-Reyes IG, et al. Detection of cannabinoid receptors $C B 1$ and $C B 2$ within basal ganglia output neurons in macaques: changes following experimental parkinsonism. Brain Struct Funct. 2015;220:2721-38. 